\title{
Assessment on the Impacts of Road Geometry and Route Selection on Road Safety: A Case of Mettu-Gore Road, Ethiopia
}

\author{
Alamirew Mulugeta Tola ${ }^{1, *}$, Alemayehu Gebissa ${ }^{2}$ \\ ${ }^{1}$ Faculty of Civil \& Environmental Engineering, Jimma Institute of Technology, Jimma University, Jimma, Ethiopia \\ ${ }^{2}$ Faculty of Agricultural and Environmental Sciences, Chair of Geotechnics and Coastal Engineering, Rostock University \\ *Corresponding author: lolaal728@gmail.com
}

Received November 17, 2018; Revised January 16, 2019; Accepted January 24, 2019

\begin{abstract}
The objective of this paper is twofold; First, it develops an excel program referring to the governing values of Geometric design manual of Ethiopia in order to identify and quantify inconsistent geometric design on Mettu-Gore road. In order to achieve the first fold of the study, the final As-built geometric design on Mettu-Gore road and the geometric design policy of Ethiopia have been used. Second, it assesses the geometric characteristics of police-reported hotspot zones of the road. The result was confirmed that road geometric parameters such as; Radius of a curve, Superelevation, Gradient, and Sight distance are the most significant factors affecting road safety on Mettu-Gore road.
\end{abstract}

Keywords: AADT, grade, radius of a curve, sight distance, and Superelevation

Cite This Article: Alamirew Mulugeta Tola, and Alemayehu Gebissa, "Assessment on the Impacts of Road Geometry and Route Selection on Road Safety: A Case of Mettu-Gore Road, Ethiopia." American Journal of Civil Engineering and Architecture, vol. 7, no. 1 (2019): 13-19. doi: 10.12691/ajcea-7-1-2.

\section{Introduction}

In order to attain the primary goal of road transportation, road designers and their disciplines need to use different emerging technologies and techniques. Analysis of geometric design consistency has been used widely to improve the safety of the roads. Geometric design consistency can be demarcated as how a driver's expectations and the road's performance match up (i.e., when a road with good consistency level matches a driver's expectations, the road user is not amazed while driving along it) [1]. Design consistency corresponds to relating the design speed with actual driving behavior, which is expressed, by the $85^{\text {th }}$ percentile speed of passenger cars under free-flow conditions [2].

Road safety is one of the great problems worldwide since it touches the socio-economy of the country in advance. One of the most cost-effective road safety interventions is to eliminate so-called hotspots, that is, to remedy accident-prone locations along the roads. This comprises the following steps; identify the hotspots, learning the problems (diagnosis) at each spot, design suitable safety mitigations, estimate their effects, set priorities, implement, and finally, follow up and evaluate the results [3].

The major contributing factors to the occurrence of Road Traffic Accidents (RTAs) are roadway geometry, driver error, vehicle factor, and environmental factor. According to Rumar K. [4], accidents occurred 57\% due to driver factor, $27 \%$ due to the combined roadway and driver factor, $6 \%$ due to the combined vehicles and deriver factor, $3 \%$ due to roadway factor, $3 \%$ due to the combination of the road, drivers, and vehicles, $2 \%$ due to vehicle factor, $1 \%$ due to the combined vehicle and road user factor. About $60 \%$ of Road Traffic Accidents (RTAs) are caused due to driver-related behavior [5]. Road network in Africa is expanding fast, and similarly, maintenance standards are improved resulting safer design standard of the road. However, in Ethiopia, due to lack of training on the subject area, contribution of roads and environment to traffic accidents are underestimated.

The effects of road geometry and route selection on accident rates are an ongoing argument amongst academic researchers and transportation bodies. In addition to 'driver error', road geometric design characteristics affect the safety of the road in advance. A number of studies carried out by British transportation bodies on rural roads in order to correlate personal injury and accident rates with horizontal curvature and suggest that accident rates are unlikely to be affected by moderate changes in road design parameters. Road geometry is a significant cause of road accidents. In the previous studies, it is widely accepted that elements of road geometry such as horizontal curvature and sight distance are the significant factor to accident rates. This is illustrated in the early work by researchers $[6,7,8]$, who all reports the increasing of crash rates as a result of road curvature.

Most of the past studies show that accidents often occur at curves. Ding Jianmei \& Pei Yulong in their study 
conducted on Shenda freeway, they explores the close relationship between accident rate and curve radius. Which is a small radius, inserted into the long and straight line, is dangerous and risky. Finally, the study concludes that modification of the horizontal alignment is one of the effective countermeasures for Road Traffic Accidents [9]. Crests affect sight distance, which means that drivers cannot perceive information about the road ahead and slow down if this is necessary [10]. Sags or dips affect sight distance at night, as headlight have a restricted vertical range [11]. Roy Jorgensen suggested that Steeper grades are generally associated with higher crash rates [12].

By constructing new infrastructure, mobility in urban areas can be improved. However, this needs a long period of time and expensive. For a short-term solution, it is feasible to improve the traffic management system to rationalize the use of the existing infrastructure [13]. Nowadays, traffic management and control in developing countries are weak [14]. The road geometry by itself has its own contribution to traffic crashes next to driver error. Studying the geometric design consistency is a crucial phase in road safety improvement

\section{Methods and Material}

\subsection{Study Area}

The research was conducted on Mettu-Gore road which is found in Oromia Region Ilu Abba Bora Zone, Ethiopia. The road is found in the latitude of 8016'0" $\mathrm{N}$ and longitude of 35034'60" E in Mettu town to the latitude of 809 '4.83" N and longitude of 35032'8.47' E in Gore town.

\subsection{Data Collection}

The following data were collected and used as input and supporting features to assess the geometric characteristics of the road.

\subsubsection{Road Geometric Design}

The final As-built Mettu-Gore road geometric design was collected from Ethiopian Roads Authority (ERA), Jimma district. From these, the extracted data includes:

- Roadway width these are; number of lanes, lane width (m), side slope (\%);

- Vertical Alignment (grade on a tangent (\%), grade on a curve (\%), sight distance in terms of $\mathrm{K}$ value, curve length (m));

- Horizontal alignment (radius of a curve (m), the rate of superelevation $(\%)$, length of runoff $(\mathrm{m}))$;

- Median (median width (m)).

\subsubsection{Traffic Data}

Cameron et al [15], noted that if Average Annual Daily Traffic (AADT) volumes are unavailable, estimates will often suffice since the calculation of exposure is not sensitive to minor estimation errors. Similarly, when AADT data for every year is not found, interpolation between years can be done. Thus, in this study AADT data were collected from the average daily traffic report of ERA (2013) that were summarized by districts in 2012 .

\subsubsection{Map of Mettu-Gore Road}

The geographical and structural plan Maps of Mettu and Gore town were collected from Ethiopian Mapping Agency (EMA) and Oromia Master Plan Institute (OMPI). Which is helpful to mark or digitize the defective segments of the road and to identify gentle gradient alternative routes by analyzing the topographic data.

\subsection{Data Processing and Analysis}

After collecting all the necessary information, data processing and interpretation of the first fold was done by developing an excel program in reference to the governing values of geometric design specified in the standard. And then, the existing or the final As-built geometric parameters were compared with the governing standard values according to the affecting factors of geometric parameters i.e. design speed, topography, design capacity, and AADT. Finally, the defective segments of the road were identified and located on the digitized map of the road. The flow chart in Figure 1 summarizes data processing and analysis of the first fold of this study.

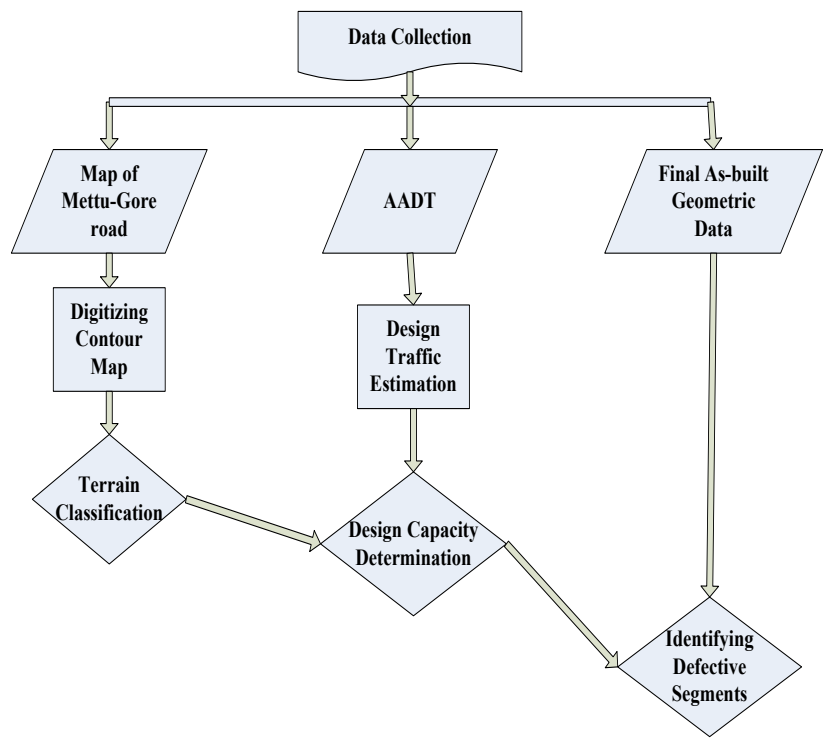

Figure 1. Flow chart of data processing and analysis of the first fold

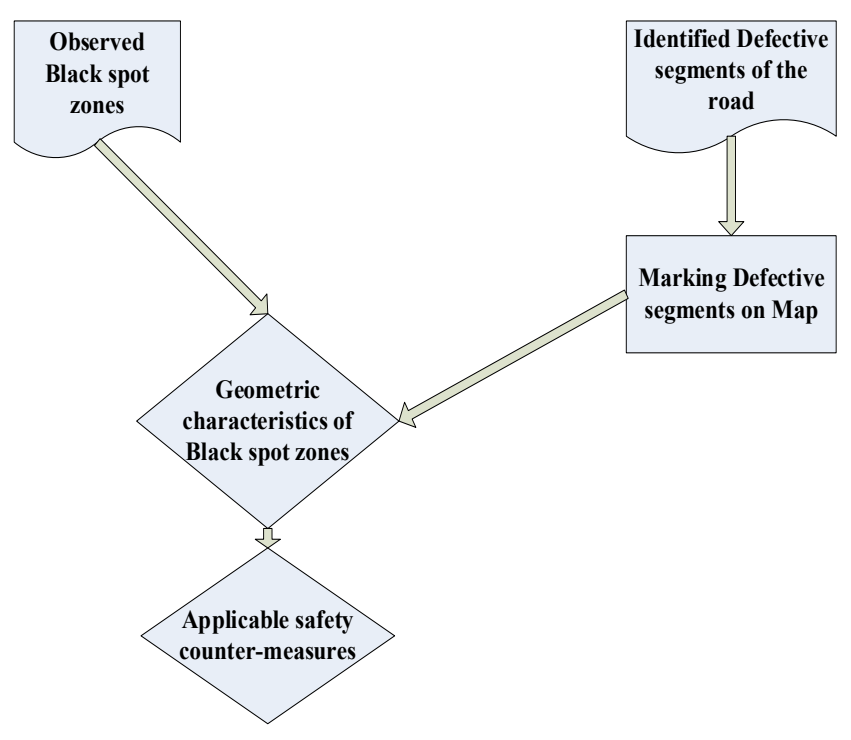

Figure 2. Flow chart of data processing and analysis of the second fold 
Table 1. The Design Speeds Given in ERA Manual, 2013 for DC5 [16]

\begin{tabular}{|c|c|c|c|c|c|}
\hline Terrain Type & Flat Terrain & Rolling Terrain & Mountainous Terrain & Escarpment Terrain & Urban/Peri-Urban \\
\hline Design Speed $(\mathrm{Km} / \mathrm{hr})$ & 85 & 70 & 60 & 50 \\
\hline
\end{tabular}

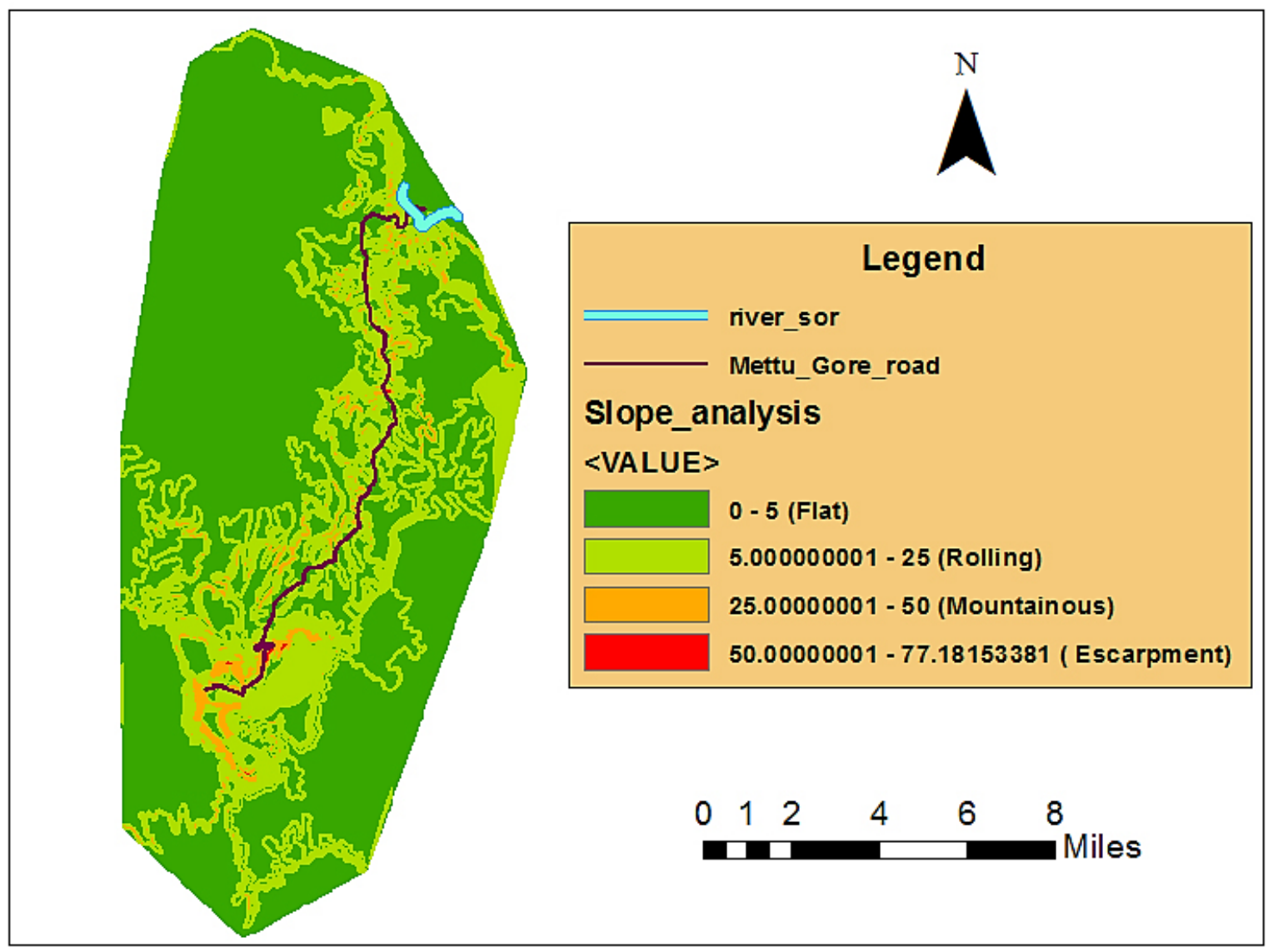

Figure 3. Slope analysis of Mettu-Gore road

By linking the hazardous locations with geometric assessment output, the geometric characteristics of the police-reported hazardous section of the road were determined and the applicable safety countermeasures have been recommended according to the geometric design inconsistency detected in the second fold of this study. The data processing and analysis of the second fold of this study is presented in Figure 2.

AADT of the road from Mettu to Gore that was counted and summarized by the district was 781 with a traffic growth rate of $3.5 \%$ (Source: ERA, Annex 1-Average Daily Traffic summarized by district) [16]. Thus, estimating the AADT at the traffic opening (the year the road is opened for traffic) of Mettu-Gore road (2010) and design traffic flow at mid-life, the Design Standard of Mettu-Gore road fall in a category of Design Class five (DC5) according to ERA Geometric Design Manual, 2013.

Terrain type of Mettu-Gore road was analyzed by using a slope analysis tool of ArcGIS (10.2) and the result is shown in Figure 3.

\section{Results and Discussions}

\subsection{Assessment of Horizontal Alignment}

A radius of a curve and superelevation of the existing road were evaluated and the results confirmed that nineteen (19 out of 86 ) curves are out of standard. See Figure 4.

\subsection{Assessment of Vertical Alignment}

Sight distance and gradients of the existing vertical alignment were assessed and the result had shown that sixteen (16 out of 88 ) vertical curves with inadequate sight distance and eleven (11) high gradient vertical tangents are found on Mettu-Gore road. See Figure 5.

\subsection{Characteristics of Police-Reported Hotspot Segments on Mettu-Gore Road}

According to the local traffic police reports, on MettuGore road, there are four (4) segments of the roadway which are observed in recurrence of crashes. These are "Arat-kilo" square, 'S-curve' entrance to Gore town, "Bechano and Gagi" area, and "Sor" bridge area.

\subsection{1. "Arat-kilo" Square}

In "Arat-kilo" square sharp curve, steeper gradient provision and inadequate sight distance (SD) provision are the detected design inconsistency. The existing value and standard values are discussed in Table 2 and Figure 6. 


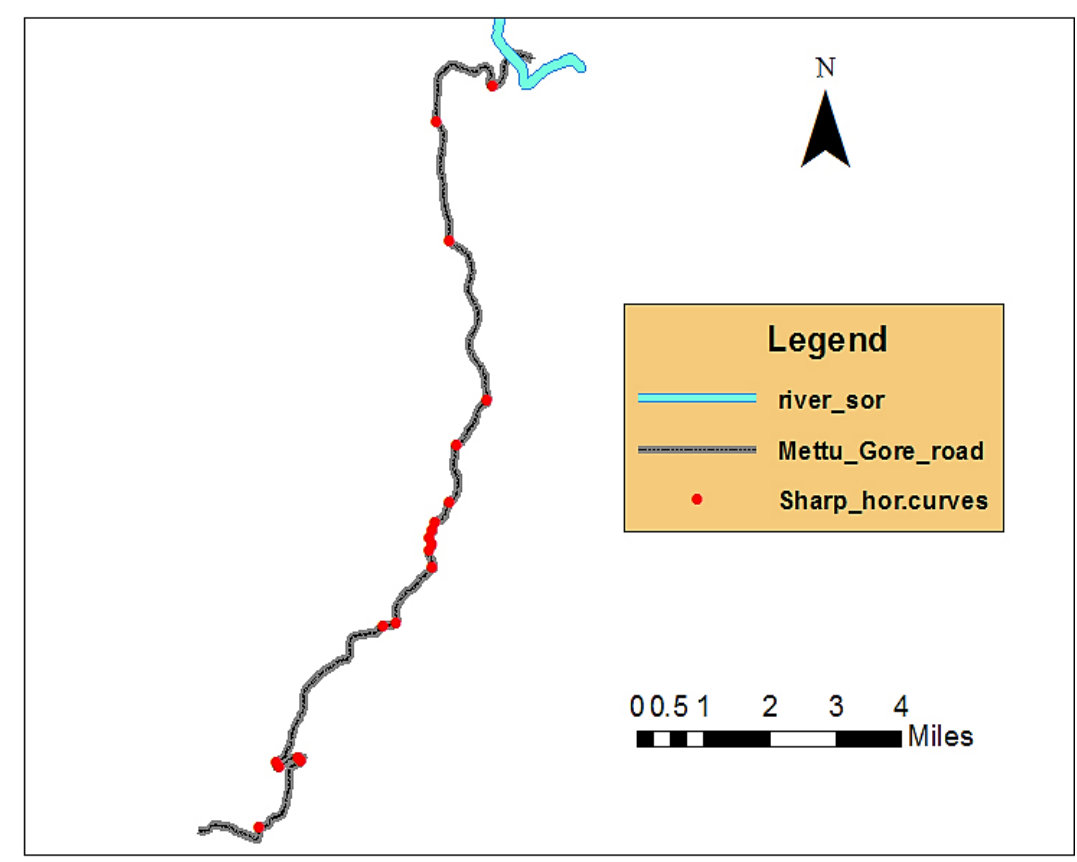

Figure 4. Defective horizontal alignment

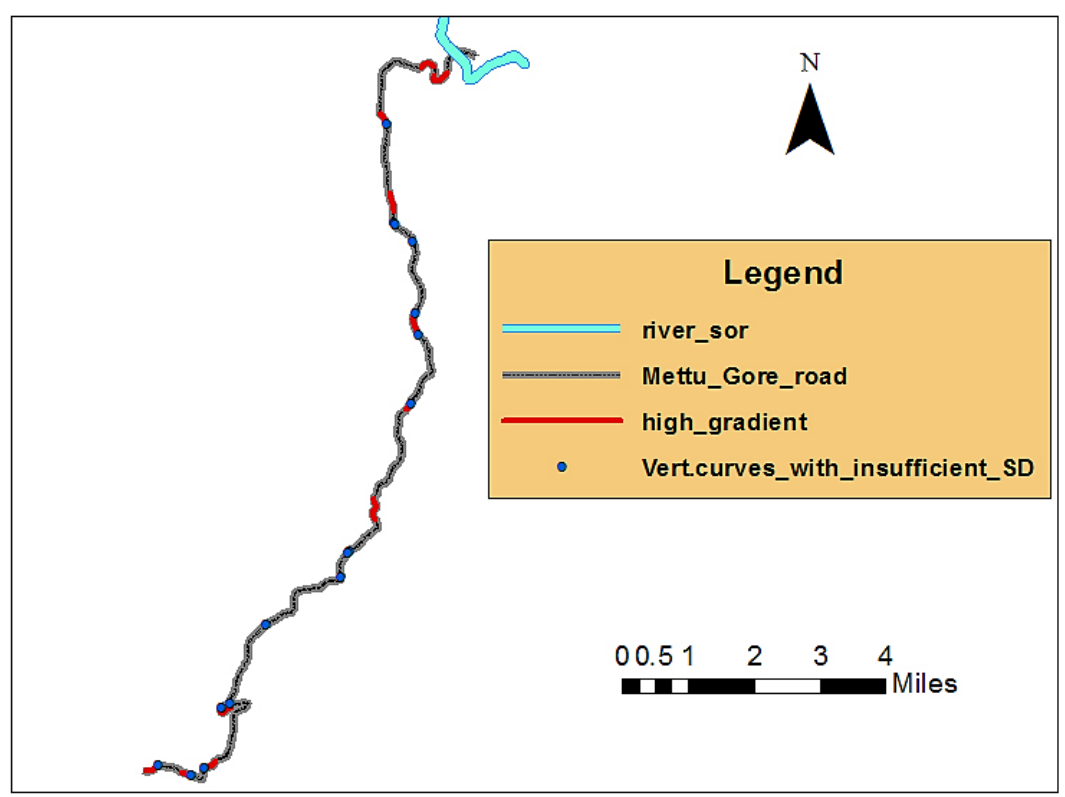

Figure 5. Defective vertical alignment

Table 2. Geometric Elements Departed from Standard on the First Crash Hotspot

\begin{tabular}{|c|c|c|c|}
\hline Curve No. & Description & $\begin{array}{c}\text { Existing } \\
\text { Value }\end{array}$ & $\begin{array}{c}\text { Standard } \\
\text { Value }\end{array}$ \\
\hline 13 (Horizontal curve) & Sharp curve & $\mathrm{R}=85 \mathrm{~m}$ & $\mathrm{R}=145 \mathrm{~m}$ \\
\hline 15 (Vertical curve) & High gradient & $\mathrm{G}=9.94 \%$ & $\mathrm{G}=7 \%$ \\
\hline 15 (Vertical curve) & $\begin{array}{c}\text { Inadequate } \\
\text { sight distance }\end{array}$ & $\mathrm{K}=8.378$ & $\mathrm{~K}=10$ \\
\hline
\end{tabular}

- Recommended Safety mitigations:

The contour data found on the structural plan Map of Mettu town shows there is an alternative gentle gradient minor road with a safe radius of curvature. For future upgrading, this minor road should have to be used as the alternative route by replacing the first accident hotspot segment of the road.

The recommended safety countermeasures in this area are adopted by speed management techniques of the enforcement speed control system. This is; Provision of the adequate roundabout which lets driver negotiate themselves for rotary by reducing their speed, construction of Transverse ramps on the straight high gradient segment of the road thus enforcing the drivers to reduce their speed while passing the ramp, and provision of Traffic signal at "Arat-Kilo" square.

\subsection{2. 'S-curve' Entrance to Gore Town}

The existing and standard values are discussed in numeric value Table 3 and map description Figure 7.

- Recommended Safety countermeasures:

Providing safety barriers for the first turn of the high gradient sharp horizontal curves and warning sign and speed limit posts on both entrance sides are found critical safety mitigations which give drivers a sign of careful driving. Also, the study recommends, removing 
obstruction from a clear sight line of drivers since trees and mountains are densely found inside the clear sight distance.

Table 3. Geometric Elements Departed from Standard on the Second Crash Hotspot

\begin{tabular}{|c|c|c|c|}
\hline Curve No. & Description & $\begin{array}{c}\text { Existing } \\
\text { Value }\end{array}$ & $\begin{array}{c}\text { Standard } \\
\text { Value }\end{array}$ \\
\hline 65 (Horizontal curve) & Sharp curve & $\mathrm{R}=55 \mathrm{~m}$ & $\mathrm{R}=120 \mathrm{~m}$ \\
\hline 66 (Horizontal curve) & Sharp curve & $\mathrm{R}=55 \mathrm{~m}$ & $\mathrm{R}=120 \mathrm{~m}$ \\
\hline 68 (Horizontal curve) & Sharp curve & $\mathrm{R}=61.5 \mathrm{~m}$ & $\mathrm{R}=120 \mathrm{~m}$ \\
\hline 69 (Horizontal curve) & Sharp curve & $\mathrm{R}=61.5 \mathrm{~m}$ & $\mathrm{R}=120 \mathrm{~m}$ \\
\hline 70 (Vertical curve) & $\begin{array}{c}\text { Inadequate sight } \\
\text { distance }\end{array}$ & $\mathrm{K}=13.411$ & $\mathrm{~K}=18$ \\
\hline 71 (Vertical curve) & $\begin{array}{c}\text { Inadequate sight } \\
\text { distance }\end{array}$ & $\mathrm{K}=12.421$ & $\mathrm{~K}=18$ \\
\hline 72 (Vertical curve) & High gradient & $\mathrm{G}=9.41 \%$ & $\mathrm{G}=8 \%$ \\
\hline
\end{tabular}

\subsection{3. "Bechano and Gagi" Area}

Table 4 and Figure 8 discusses the characteristics of the "Bechano and Gagi" area.

- Recommended Safety countermeasures

Providing warning signposts to offer information to driver's that, there is a dangerous continuous zigzagged curve ahead. Also, increase the curve widening on this zigzagged curve since the widening is inadequate so as to treat the psychological comfort of drivers.

\subsection{4. "Sor-bridge" Area}

On the outer side of the sharp curve, villages and coffee processing houses are found with the lowest altitude, this may increase the severity of the accident in this area. Thus, the implementation of lighting columns and safety barriers on the sharp curve is recommended to reduce the severity of accidents. Speed limit and warning signposts should have to be provided.

Table 4. Geometric Elements Departed from Standard on the Third Crash Hotspot

\begin{tabular}{|c|c|c|c|}
\hline Curve No. & Description & $\begin{array}{c}\text { Existing } \\
\text { Value }\end{array}$ & $\begin{array}{c}\text { Standard } \\
\text { Value }\end{array}$ \\
\hline 39 (Horizontal curve) & Sharp curve & $\mathrm{R}=85 \mathrm{~m}$ & $\mathrm{R}=120 \mathrm{~m}$ \\
\hline 40 (Horizontal curve) & Sharp curve & $\mathrm{R}=85 \mathrm{~m}$ & $\mathrm{R}=120 \mathrm{~m}$ \\
\hline 41 (Horizontal curve) & Sharp curve & $\mathrm{R}=85 \mathrm{~m}$ & $\mathrm{R}=120 \mathrm{~m}$ \\
\hline 42 (Horizontal curve) & Sharp curve & $\mathrm{R}=65 \mathrm{~m}$ & $\mathrm{R}=175 \mathrm{~m}$ \\
\hline 43 (Horizontal curve) & Sharp curve & $\mathrm{R}=75 \mathrm{~m}$ & $\mathrm{R}=175 \mathrm{~m}$ \\
\hline 45 (Horizontal curve) & Sharp curve & $\mathrm{R}=125 \mathrm{~m}$ & $\mathrm{R}=175 \mathrm{~m}$ \\
\hline 50 (Horizontal curve) & Sharp curve & $\mathrm{R}=72 \mathrm{~m}$ & $\mathrm{R}=175 \mathrm{~m}$ \\
\hline 51 (Horizontal curve) & Sharp curve & $\mathrm{R}=145 \mathrm{~m}$ & $\mathrm{R}=175 \mathrm{~m}$ \\
\hline 49 (Vertical curve) & $\begin{array}{c}\text { High gradient } \\
\mathrm{G}=8.51 \%\end{array}$ & $\mathrm{G}=6 \%$ \\
\hline 52 (Vertical curve) & $\begin{array}{c}\text { Inadequate } \\
\text { sight distance }\end{array}$ & $\mathrm{K}=29.25$ & $\mathrm{~K}=31$ \\
\hline 53 (Vertical curve) & $\begin{array}{c}\text { Inadequate } \\
\text { sight distance }\end{array}$ & $\mathrm{K}=18.725$ & $\mathrm{~K}=25$ \\
\hline 55 (Vertical curve) & $\begin{array}{c}\text { Inadequate } \\
\text { sight distance }\end{array}$ & $\mathrm{K}=12.694$ & $\mathrm{~K}=25$ \\
\hline
\end{tabular}

Table 5. Geometric Elements Departed from Standard on the Fourth Crash Hotspot

\begin{tabular}{|c|c|c|c|}
\hline Curve No. & Description & $\begin{array}{c}\text { Existing } \\
\text { Value }\end{array}$ & $\begin{array}{c}\text { Standard } \\
\text { Value }\end{array}$ \\
\hline 3 (Horizontal curve) & Sharp curve & $\mathrm{R}=82 \mathrm{~m}$ & $\mathrm{R}=175 \mathrm{~m}$ \\
\hline 4 (Vertical curve) & High gradient & $\mathrm{G}=8.23 \%$ & $\mathrm{G}=7 \%$ \\
\hline 6 (Vertical curve) & High gradient & $\mathrm{G}=8.84 \%$ & $\mathrm{G}=7 \%$ \\
\hline
\end{tabular}

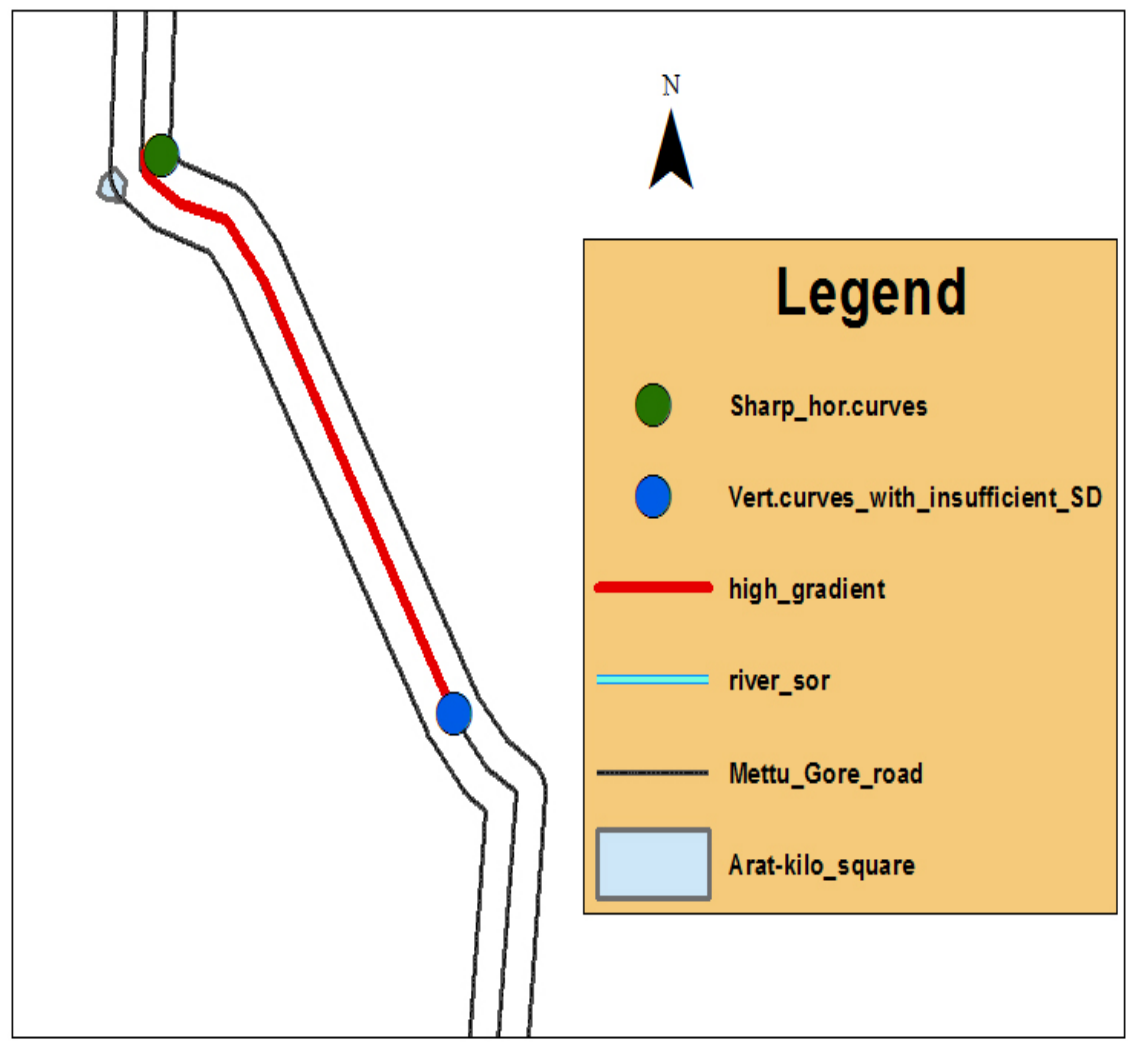

Figure 6. Map showing Geometric characteristics of the first crash hotspot area 


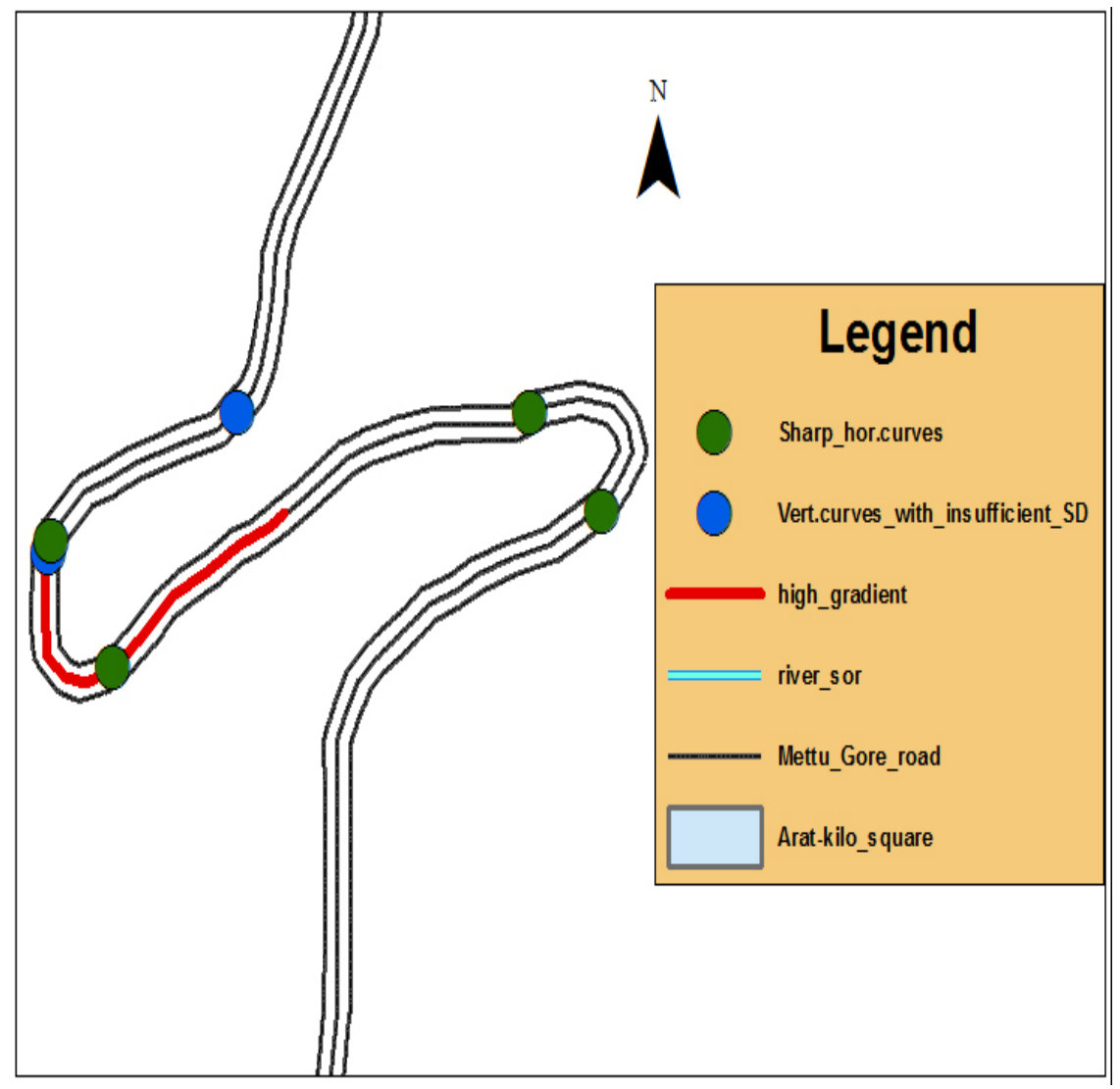

Figure 7. Map showing Geometric characteristics of the second crash hotspot area

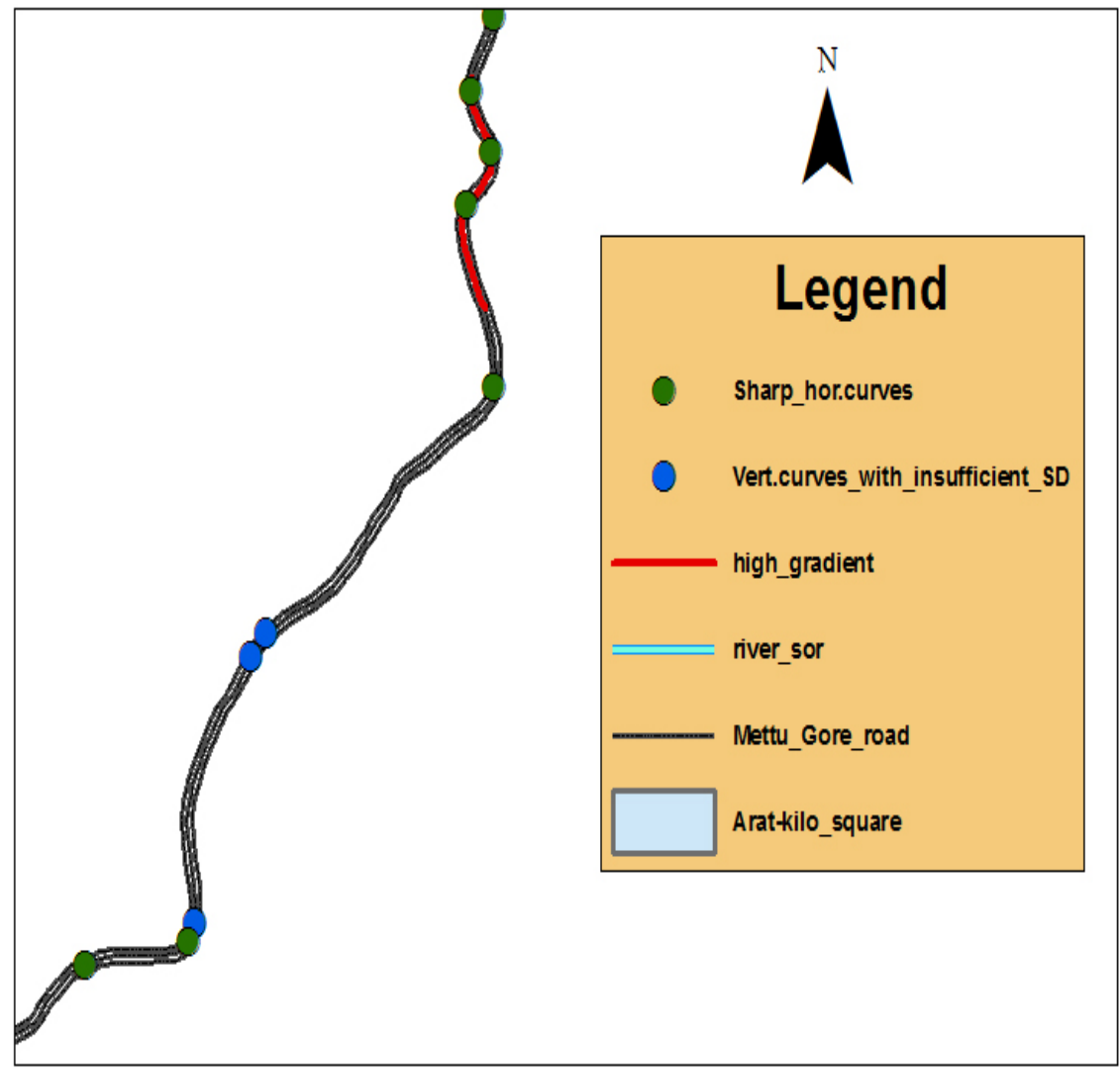

Figure 8. Map showing Geometric characteristics of the third crash hotspot area 


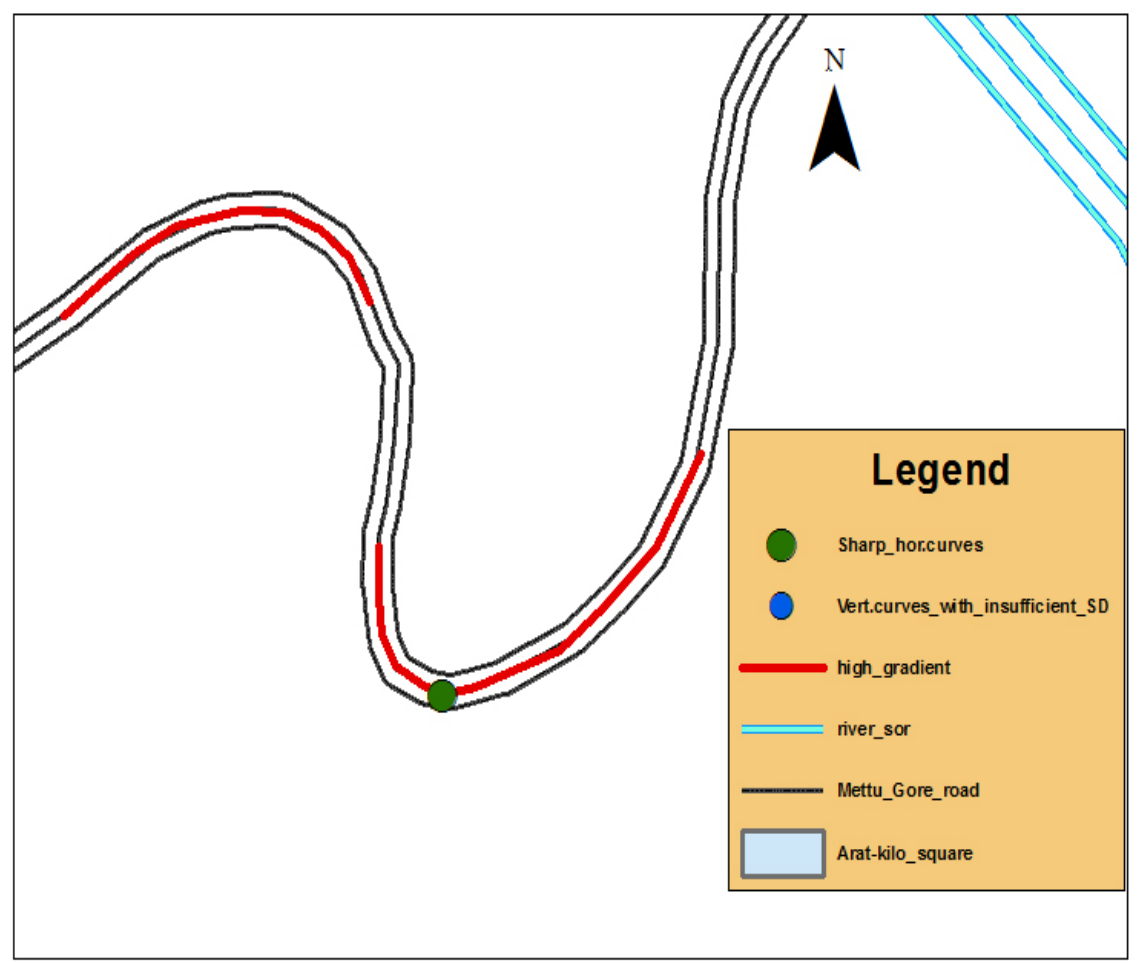

Figure 9. Map showing Geometric characteristics of the fourth crash hotspot area

\section{Conclusion}

The study has investigated the impacts of road geometry and route selection on road safety. The results from geometric assessment have shown that road sections that combine inadequate sight distance, high gradient, and sharp curves bend with insufficient superelevation would have produce higher safety problems.

Based on deep understanding on the effects of road geometry and route selection on road safety, the safety solutions should be considered to minimize the current high frequency and severity of accidents at the police reported hotspots for the most ranked areas. The proposed details in the results and discussion parts were given and the recommended safety countermeasures must have to be implement in order to have a normal traffic flow.

\section{References}

[1] F. J. Camacho-Torregrosa, A. M. Pérez-Zuriaga, J. M. CampoyUngría, and A. García-García, "New geometric design consistency model based on operating speed profiles for road safety evaluation," Accid. Anal. Prev., vol. 61, pp. 33-42, 2013.

[2] R. Lamm, B. Psarianos, and T. Mailaender, "Highway design and traffic safety engineering handbook," 1999.

[3] A. General Directorate of Highways, "Road Improvement and Traffic Safety Project : Black spot manual,” Ankara, 2001.
[4] K. Rumar, "The Role of Perceptual and Cognitive Filters in Observed Behavior," Hum. Behav. Traffic Saf., pp. 151-170, 1985.

[5] L. Evans, "The dominant role of driver behavior in traffic safety.," Am. J. Public Health, vol. 86, no. 6, pp. 784-786, 1996.

[6] P. Cairney and A. McGann, "Relationship between crash risk and geometric characteristics of rural highways," p. 61p, 2000.

[7] B. Persaud, R. Retting, and C. Lyon, "Guidelines for Identification of Hazardous Highway Curves," Transp. Res. Rec. J. Transp. Res. Board, vol. 1717, pp. 14-18, 2000.

[8] N. D. Antonucci, "Guidance for Implementation of the AASHTO Strategic Highway Safety Plan: A guide for reducing work zone collisions," Transp. Res. Board Natl. Acad., 2005.

[9] D. Jianmei and P. E. I. Yulong, "Influence of Road Conditions on Traffic Accidents and Safety Countermeasures *," Procedia Eng., vol. 2, no. 1, pp. 2011-2015, 2011.

[10] B. Fildes and S. Lee, "The Speed Review: road environment, behavior, speed limits, enforcement and crashes," p. 147, 1993.

[11] G. Dietze, M., Ebersach, D., Lippold, C., Mallschuttzke, K., \& Gatti, "Road Geometric, Driving Behavior, and Road Safety," 2005.

[12] Roy Jorgensen and Associates, "Cost and Safety Effectiveness of Highway Design Elements.," Natl Coop Highw Res Progr. Rep, no. $197,1978$.

[13] R. Gakenheimer, "Urban mobility in the developing world," Transp. Res. Part A Policy Pract., vol. 33, no. 7-8, pp. 671-689, 1999.

[14] K. Gwilliam, "Urban transport in developing countries," Transp. Rev. A Transnatl. Transdiscipl. J., vol. 23, no. 2, pp. 197-216, 2003.

[15] C. M. and F. B. Sanderson JT, "Identification of hazardous road locations," Canberra, 1985.

[16] Ethiopian Roads Authority (ERA), "Geometric Design Manual." 2013. 